\title{
Are mindfulness skills associated with reducing kinesiophobia, pain severity, pain catastrophizing and physical disability? Results of Iranian patients with chronic musculoskeletal pain
}

\begin{abstract}
BACKGROUND
Although the results obtained for mindfulness-based treatments are promising, there is limited information concerning the role of different dimensions of mindfulness in the undesirable outcomes related to chronic pain such as physical pain and catastrophizing, pain severity, kinesiophobia and disability. Therefore, the objective of this present research was to examine the relationship between facets of mindfulness and the mentioned outcomes in individuals with musculoskeletal pain (MSP), including an extensive population of patients.
\end{abstract}

\section{PARTICIPANTS AND PROCEDURE}

In a cross-sectional research, 200 patients with chronic MSP were selected from northern Iran by the consecutive sampling method and were assessed through the Five Facet Mindfulness Questionnaire (FFMQ), Visual Analogue Scale (VAS), 24-item Roland Morris Disability Questionnaire (RMDQ-24), 17-item Tampa Scale of Kinesiophobia (TSK-17), and the Coping Strategies Questionnaire - Catastrophizing subscale (CSQ-CAT).

\section{RESULTS}

Results were obtained via multivariate hierarchical regression analyses after adjusting for the effects of demographic variables, revealing that higher scores in the Observing subscale can predict lower scores in the VAS. Moreover, higher scores in the Describing subscale predict higher scores in VAS, CSQ-CAT and TSK-17; higher scores in Acting with Awareness predict lower scores in VAS and CSQ-CAT; higher scores in Non-judging predict lower scores in VAS, RMDQ-24 and TSK-17; finally, higher scores in Non-reactivity predict higher scores in RMDQ-24 and TSK-17.

\section{CONCLUSIONS}

All factors existing in mindfulness are associated to MSP after controlling for certain undesirable outcomes. It seems that mindfulness interventions can potentially result in clinical improvement of patients suffering from chronic musculoskeletal pain.

\section{KEY WORDS}

musculoskeletal pain; mindfulness; disability; catastrophizing

ORGANIZATION - Department of Psychology, Faculty of Literature and Humanities, University of Guilan, Rasht, Iran aUthors' contributions - A: Study design - B: Data collection - C: Statistical analysis - D: Data interpretation .

E: Manuscript preparation · F: Literature search · G: Funds collection

Corresponding Author - Prof. Sajjad Rezaei, Department of Psychology, Faculty of Literature and Humanities, University of Guilan, Khalij Fars Highway, 41998-43653 Rasht, Iran, e-mail: rezaei_psy@hotmail.com

TO CITE THIS ARTICLE - Rezaei, S., \& Hassanzadeh, S. (2019). Are mindfulness skills associated with reducing kinesiophobia, pain severity, pain catastrophizing and physical disability? Results of Iranian patients with chronic musculoskeletal pain. Health Psychology Report. https://doi.org/10.5114/hpr.2019.84747

RECEIVED 04.01.2019 • REVIEWED 17.03.2019 • ACCEPTED 18.03.2019 • PUBLISHED 26.04.2019 


\section{BACKGROUND}

Pain is an inevitable component of life (Braams, Blechert, Boden, \& Gross, 2012) and a common problem in the normal and clinical populations (Sengupta \& Kumar, 2005). Although pain is generally a transient experience, for some people, it continues beyond an adaptive response to an acute damage, resulting in emotional turmoil, for which treatment, the existing sources in health care systems are employed (Otis, 2007). According to the definition of the International Association for the Study of Pain (IASP), pain is an unpleasant emotional and sensory experience resulting from real or potential tissue damage (Harvey, 1995). The sensory aspect of pain suggests that pain severity and its emotional aspect indicate unpleasant pain experience (Lumley et al., 2011). Chronic pain is considered to continue up to 6 months (Keefe \& Williams, 1990).

Prevalence of chronic pain in every individual's life is $11 \%$ to $84 \%$ (Walker, 2000). In Iran, the prevalence rate of chronic pain and recurrent chronic pain is $14 \%$ and $15 \%$, respectively (Asgharimoghaddam, 2004). Musculoskeletal chronic pain is a prevalent disease affecting 17 to $35 \%$ of adults in the general population (Thron, 2017; Taylor, Dean, \& Siegert, 2006). Chronic pain further entails considerable financial costs both for society and suffering individuals (Smolen, 2004).

The IASP has described pain and its outcomes as a complicated perception experience affected by extensive psycho-social factors. Therefore, explaining pain and its outcomes using a bio-pattern is not possible, and biological, psychological and social aspects also have to be considered (Asgharimoghaddam \& Golak, 2005). For this reason, researchers have recently developed a tendency towards examining the association between different psychological concepts and chronic pain and the effect of treatments based on these concepts, one of which is the presence of mind, mindfulness, by conscious attention to the present time (Falkenström, 2010).

Mindfulness is described as an awareness emerging from purposefully and non-judgmentally paying attention to the present moment (Kabat-Zinn, 1990). In other words, mindfulness is a quality of consciousness and attention to the present moment (Kabat-Zinn \& Hanh, 2009). Mindfulness also refers to living in the moment, without judgment and giving opinion about what happens, hence the experience of pure reality without explanation (Segal, Williams, \& Teasdale, 2013). Mindfulness helps people understand that although negative emotions happen, they are not fixed components of life, helping the individual to react through reflection and thought (Bishop et al., 2006; Azad Marzabadi \& Hashemi Zadeh, 2014). Accordingly, mindfulness is a modern style for a more efficient relationship with life, especially in western societies, resulting in pain relief and richer and more pleasurable life experiences (Siegel, 2010). In the first attempts, Kabat-Zinn, Lip- worth, Burney, and Sellers (1986) explained the process of pain reduction in their projects on mindfulness and meditation. In their research, the process of pain reduction occurred by "an attitude of detached observation toward a sensation when it becomes prominent in the field of awareness and to observe with similar detachment the accompanying but independent cognitive processes which lead to evaluation and labeling of the sensation as painful." Thus, by "uncoupling" the physical sensation from the emotional and cognitive experience of pain, it is reduced.

Baer, Smith, Hopkins, Krietemeyer, and Toney (2006) introduced the Five Facet Mindfulness Questionnaire (FFMQ), showing that mindfulness has various constructs, such as Observing (including attention to external and internal stimuli such as feelings, cognition, emotion, sounds and smells), Acting with Awareness (acting and behaving with full awareness in contrast to automatic and habitual actions leading to thinking about other things), being Non-judging (intrinsically meaning non-judgment toward ideas and emotions, and just being aware of feelings and ideas without passing judgments on them), Describing (relevant to ability of naming external experiences using words) and Non-reactivity (meaning not reacting to internal experiences and allowing these thoughts to come and go without personal interference).

An overview of different studies shows that mindfulness-related treatments have had desirable effects in various areas. An increase in mindfulness results in significant and effective reduction in psychological distress, stress (Carmody \& Baer, 2007), the likelihood of relapsing depression (Sanders \& Lam, 2010), neuroticism and anxiety (Azad Marzabadi \& Hashemi Zadeh, 2014; Brown \& Ryan, 2003), and increase in well-being (Carmody \& Baer, 2007; Herndon, 2008), and the ability to compromise and improve the emotional performance (Gardner-Nix, 2009). A study has recently proposed that mindfulness practices could potentially encourage eating palatable foods (such as being motivated to eat when people are hungry), and not eating foods that lead to weight dysregulation (Mantzios \& Egan, 2018).

Regarding pain, Beks et al. (2017), in a sample of patients with upper extremity illness, found that high levels of mindfulness particularly concerning non-reactivity resulted in lower pain severity and more physical function. Furthermore, an 8-week web-based training course on mindfulness in patients with chronic pain resulted in more satisfaction with life (Henriksson, Wasara, \& Rönnlund, 2016). In a population of cancer survivors living with chronic neuropathic pain, it was also reported that higher scores in mindfulness were accompanied by lower pain severity and pain catastrophizing. As can be inferred, non-judging and acting with awareness have played more effective roles (Poulin et al., 2016).

To the best of our knowledge, no research has investigated the relationship between mindfulness skills 
and kinesiophobia, which is effective for the physical disability related to pain and pain intensity (Gutke, Lundberg, Östgaard, \& Öberg, 2010); nonetheless in the context of the fear-avoidance model, Jay et al. (2016) found that performing 10 weeks of physical-cognitive mindfulness intervention resulted in the reduction of fear-avoidance beliefs contributing to chronic pain. Finally, Schütze, Rees, Preece, and Schütze (2010), studying a sample of patients with chronic pain, reported that lower mindfulness entailed higher scores in pain catastrophizing and pain-related fear and alertness.

Several studies have been performed on chronic pain, but there is limited information as to the impact of mindfulness skills on controlling undesirable outcomes of chronic pain, particularly in patients with musculoskeletal problems. Accordingly, the objective of the present study was to examine whether or not mindfulness skills can reduce the undesirable outcomes of chronic pain such as kinesiophobia, pain severity, pain catastrophizing and physical disability after eliminating demographic factors and conditions related to a disease. In other words, we hypothesized that mindfulness skills would relate to reducing kinesiophobia, pain severity, pain catastrophizing and physical disability.

\section{PARTICIPANTS AND PROCEDURE}

\section{PARTICIPANTS}

The present research is a descriptive cross-sectional study on 200 patients ( 99 women and 101 men) meeting the pathologic criteria for chronic musculoskeletal pain via a consecutive sampling method. To determine the sample size, given the F ratio, version 3.1.9.2 of $\mathrm{G}^{*}$ Power software was used for 5 variables entered in the predictor block (FFMQ dimension) and 6 covariate variables including variables related to disease conditions and demography of participants (Faul, Erdfelder, Buchner, \& Lang, 2009). Considering the probability of type I error (alpha) at the .01 level (confidence level 95\%), the test power level was .95 , the moderate effect size was $f^{2}=.15$, and the sample size was equal to 180 people; in order to deal with probable outliers and unsuccessful completion of some tests (dropout), the size of the final sample was increased to 200 people. Eighty patients (40\%) had a backache, 53 patients suffered from pain in their arms and shoulders (26.5\%), and 67 had a pain in the neck and joints fibromyalgia (33.5\%). These patients participated from two major clinics related to diagnosis and treatment of musculoskeletal disorders in Rasht city, in the north of Iran, by coordination and supervision of physicians and therapists (physical medicine and rehabilitation specialists, physiotherapists and orthopedic experts) during a 3-month period (from December 21, 2017). Following examination by specialists and definite diagnosis of therapists for musculoskeletal pain, all patients were referred to a trained psycholo- gist. In order to comply with ethical conditions, before performing the psychological tests, we emphasized the protection of the clients' personal information, and patients were ensured that the data would be published as a total response of the group.

Inclusion criteria were lack of a comorbid condition (such as infectious diseases, or cancer), age at least 18 years, existence of a chronic pain for 6 months, and having sufficient literacy to complete the tests. Exclusion criteria were surgery candidates, drug abuse, and non-agreement to complete the mental evaluations and participate in the research. After obtaining the consent, patients were trained how to complete the questionnaires (especially the Visual Analogue Scale).

\section{TOOLS}

Visual Analogue Scale (VAS). Patients' pain severity was measured through the VAS indicator, which is an upgraded line between 0 and $100 \mathrm{~mm}$, where "zero" means no pain, while "100" refers to the highest pain possible. The patients were asked to determine their degree of severity at the moment on the axis in visual form. This scale has been employed in several studies and its validity and reliability have been corroborated (Ogon, Krismer, Söllner, Kantner-Rumplmair, \& Lampe, 1996; Turk \& Melzack, 2001).

Tampa Scale of Kinesiophobia (TSK-17). This tool has 17 items. A high score in this test suggests a high level of fear of moving because of pain perception. This scale is scored in Likert form in a range from 1 (totally disagree) to 4 (totally agree). Sample items are "My body is telling me I have something dangerously wrong" and "Pain always means I have injured my body". Higher scores in this scale suggest more fear of movement or more fear of (re)injury (Vlaeyen, Kole-Snijders, Rotteveel, Ruesink, \& Heuts, 1995). In Iran, Afshar-Nezhad, Rezaei, and Yousef-zadeh (2010) obtained the reliability of this tool, by Cronbach's $\alpha$, to be .84, and Jafari, Ebrahimi, Salavati, Kamali, and Fata (2010), in addition to observing desirable construct validity, reported an intraclass correlation coefficient (ICC) of .86 in the repeatability evaluation for a 17 -item version of this scale. Cronbach's $\alpha$ coefficient for TSK-17 in the present study was .70.

Roland-Morris Disability Questionnaire (RMDQ-24). Patients' physical disability was assessed through the Persian version of Roland and Morris questionnaire, and because patients in this research had pain in different parts of their body, "back pain" was eliminated from the RMDQ and was substituted by "body pain" (Asgharimoghaddam \& Golak, 2005). This questionnaire includes 24 items about functional and daily actions and the score of each item ranges from 0 meaning no disability to 24 meaning the highest disability. Sample items are "I get dressed more slowly than usual because of my body pain" and "I sleep less well because
Mindfulness skills and undesirable outcomes associated with chronic pain 
Sajjad Rezaei, Sedigheh Hassanzadeh of my body pain”. For this tool, used extensively in studies related to chronic pain, high repeatability and validity have been reported (Roland \& Fairbank, 2000; Mousavi, Parnianpour, Mehdian, Montazeri, \& Mobini, 2006). Cronbach's $\alpha$ coefficient for RMDQ-24 in the present study was .71.

Five Facet Mindfulness Questionnaire (FFMQ). This tool is a self-assessment scale of 39 items developed by Baer et al. (2006), using a factorial analysis approach. Scoring in this questionnaire is performed on a Likert scale from 1 (never) to 5 (always). These researchers conducted exploratory factor analysis on a sample of students and the obtained factors were named as follows: observing, describing, acting with awareness, non-judging of inner experience, and non-reactivity to inner experience. The stable internal consistency of each factor was appropriate and Cronbach's $\alpha$ coefficient was in the range between .75 (non-reactivity) and .91 (in describing) (Baer et al., 2006). Sample items are "I can usually describe how I feel at the moment in considerable detail" and "I disapprove of myself when I have irrational ideas". In Iran, correlation factors of FFMQ test-retest have been calculated between $r=.57$ (non-judging) and $r=.84$ (observing) (Ahmadvand \& Heydarinasab, 2013). Dehghani, Esmaeilian, Akbari, Hassanband, and Nikmanesh (2014) also reported the internal consistency of different dimensions of the FFMQ as desirable (.81 to .93). In the present research, Cronbach's $\alpha$ coefficients for five subscales of observing, describing, acting with awareness, non-judging and non-reactivity were $.76, .73, .78, .68$ and .69 , respectively. Furthermore, to study the current Five-Factor/Facet structure of the Mindfulness Questionnaire (FFMQ), confirmatory factor analysis (CFA) was used with maximum likelihood by Amos software (version 21.0). CFA showed that the $\chi^{2} / d f$ ratio was 3.1 for the five-factor structure, and the fit indices for this structural model, including the root mean square error of approximation (RMSEA) $=.089$, the normed fit index $(\mathrm{NFI})=.93$, the Tucker-Lewis index $(\mathrm{TLI})=.91$, and the Confirmatory Fit Index $(\mathrm{CFI})=.91$, were close to the standard indices (Gefen, Straub, \& Boudreau, 2000).

Subscale of catastrophizing of the Coping Strategies Questionnaire (CSQ-CAT). To assess the catastrophic thoughts related to pain, Rosenstiel and Keefe's (1983) 6-item CSQ-CAT subscale was used in the present research. Sample items are "I worry all the time about whether it will end" and "I feel like I can't go on". Each item in this subscale is scored from 0 to 6, where higher scores suggest more coping strategy associated with catastrophizing pain. Asgharimoghaddam and Golak (2005) evaluated this tool on an Iranian sample with chronic pain and concluded that the subscale of coping strategy of catastrophizing pain has desirable psychometric features with internal consistency coefficient of .80 and an acceptable validity. In addition, Rezaei, Afsharnejad, Kafi, Soltani, and Fallahkohan (2009) reported the validity of this subscale as .85, especially for patients with chronic back pain. The Cronbach's $\alpha$ coefficient for CSQ-CAT in the present study was .74 .

\section{STATISTICAL ANALYSIS}

To fulfil the research objectives, the obtained data were entered into SPSS 20 software after coding; in order to determine the relationships between variables, the Pearson prediction correlation coefficient was applied. To evaluate the difference between male and female patients, the independent Student $t$-test was used. Finally, hierarchical multivariate regression analysis was used to determine whether the scores of FFMQ subscales after controlling for demographic features were able to predict the scores related to the evaluation of pain severity variables (VAS), physical disability (RMDQ-24) and fear of movement (TSK-17) and catastrophizing pain (CSQ-CT). Before performing this analysis, we investigated the presumption of criterion variable distribution normality in the regression analysis, and the assumption of prediction error independence or lack of autocorrelation among errors.

\section{ETHICAL STANDARDS}

All procedures performed in the present study involving human participants were in accordance with the ethical standards of the institutional and/or national research committee and with the 1964 Helsinki Declaration and its later amendments or comparable ethical standards. This article does not concern any studies on animals, and the authors declare that they have no conflict of interest. Informed consent was obtained from all individual participants included in the study.

\section{RESULTS}

The average age of participants was 42.5 , ranging from 18 to 72 years old; the average history of musculoskeletal pain was 16.6 months. Table 1 shows the data of the disease and demographic conditions of the studied samples. Table 2 presents the descriptive data (average, standard deviation) and correlation coefficient of demographic and psychological variables.

Considering the results of Table 2, the average age of patients was $42.46 \pm 11.47$. Patients reported the average pain period to be $19.14 \pm 16.66$ months. The mean time of medication to improve chronic pain was $4.27 \pm 1.95$ months, where certain subjects refused to take medication despite having pain, while others reported taking medicine for 36 consecutive months. Calculation of Pearson's correlation coefficient between subscales of the FFMQ (as independent variables) and demographic and underlying features 
Table 1

Percentage and frequency of demographic and underlying features of patients with musculoskeletal pain $(n=200)$

\begin{tabular}{llcc}
\hline Variables & \multicolumn{1}{c}{ Categories } & Frequency & Percent \\
\hline Gender & Male & 101 & 50.50 \\
Job status & Female & 99 & 49.50 \\
& Office / specialist & 57 & 28.50 \\
& Skilled / professional & 45 & 22.50 \\
& Simple or manual & 16 & 8.00 \\
& Unemployed & 16 & 8.00 \\
& Retired & 17 & 24.50 \\
Marital status & Housekeeper & 49 & 20.00 \\
& Single & 40 & 80.00 \\
Mevel of education & Elementary education & 160 & 3.00 \\
& High school education & 6 & 13.00 \\
& Diploma and academic & 26 & 84.00 \\
& No & 168 & 44.50 \\
& Yes & 89 & 55.50 \\
\hline
\end{tabular}

revealed a significant association between age, education level, medication duration and pain duration and one of the FFMQ subscales $(p<.05)$. Therefore, these demographic and underlying variables were controlled as confounding factors in regression analysis. Correlation analysis showed a constant negative relationship between Observing and scores of VAS, RMDQ-24, TSK-17 and CSQ-CAT $(p<.001)$. Describing had a direct relationship with TSK-17 scores $(p<.001)$. Other results are presented in Table 2.

The independent Student $t$-test was employed to determine the difference between male and female patients in terms of demographic, underlying and psychological variables. The results showed a difference between these two groups only regarding the scores of VAS $(t=3.64, d f=198, p<.001)$, CSQ-CAT $(t=3.09$, $p=.002, d f=198)$ and Describing $(t=2.06, d f=198$, $p=.041)$. In other words, women reported greater pain severity (52.33 vs 45.84 ) and catastrophizing pain (19.93 vs 17.06$)$, while men scored significantly higher as regards Describing (28.00 vs 29.65). Considering these differences, the gender variable was further controlled in the regression analysis.

Prior to the regression analysis, criterion variable normality in the regression analysis of dependent variables scores (i.e. VAS, RMDQ-24, TSK-17 and CSQCAT) was compared with independent variables (i.e. FFMQ subscales) through a P-P normal diagram. Normal P-P diagrams show that the observed cumulative probability or points that are representative of stan- dardized residuals of criterion variables are close to one another in all variables dependent on the normal line (representative of normal distribution). Therefore, the deviation of pain severity variables (VAS), physical disability (RMDQ-24) and fear of movement (TSK-17) and catastrophizing pain (CSQ-CAT) was less than the normal distribution. In addition, given the statistical indicators of Table 3, results of the Durbin-Watson test (DW) revealed that the assumption of independence of errors to perform regression analysis was established for each dependent variable, being in an acceptable range of 1.50 to 2.50 (Coakes, Steed, \& Ong, 2010). The following are the results obtained from hierarchical multivariate regression analysis prior to and after controlling for demographic variables.

As observed in Table 3, after eliminating the effect of demographic variables, higher scores in Observing predicted significantly lower scores in TSK-17 $(\beta=-.23, p=.001)$. High scores in Describing meant significantly high scores in TSK-17 $(\beta=.13, p=.049)$, VAS $(\beta=.16, p=.020)$ and CSQ-CAT $(\beta=.19, p=.009)$. Moreover, higher scores of Acting with Awareness predicted significantly lower scores in VAS $(\beta=-.39$, $p<.001)$ and CSQ-CAT $(\beta=-.27, p=.001)$. High scores in Non-judging predicted significantly lower scores in TSK-17 $(\beta=-.22, p=.001)$, VAS $(\beta=-.14, p=.037)$ and RMDQ-24 $(\beta=-.19, p=.010)$. Ultimately, higher scores in Non-reactivity predicted significantly higher scores in TSK-17 $(\beta=.16, p=.011)$ and RMDQ-24 $(\beta=.21, p=.002)$.
Mindfulness skills and undesirable outcomes associated with chronic pain 


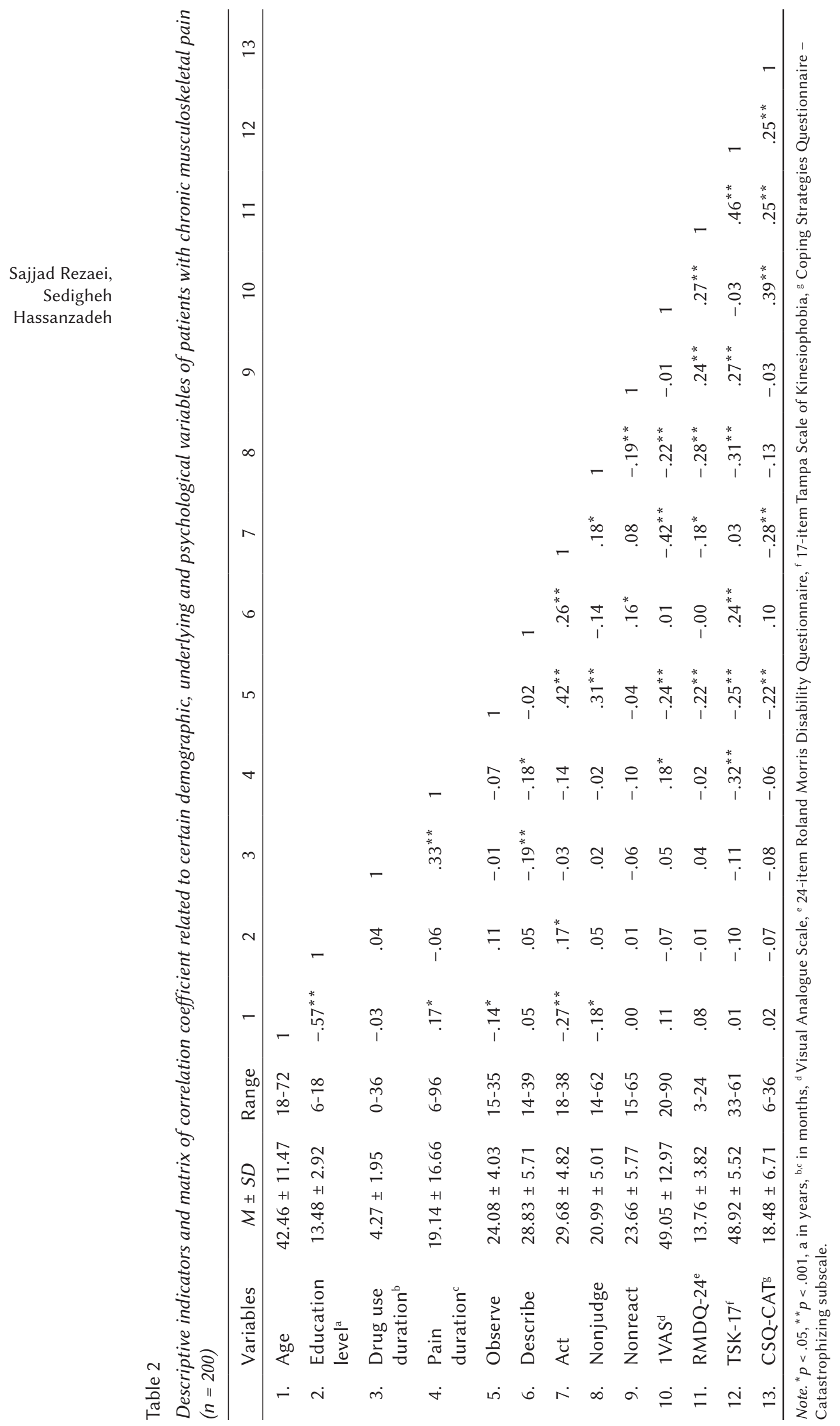


Table 3

Hierarchical multivariate linear regressions to predict scores of VAS, RMDQ-24, TSK-17, and CSQ-CAT from FFMQ subscales after controlling for demographic factors

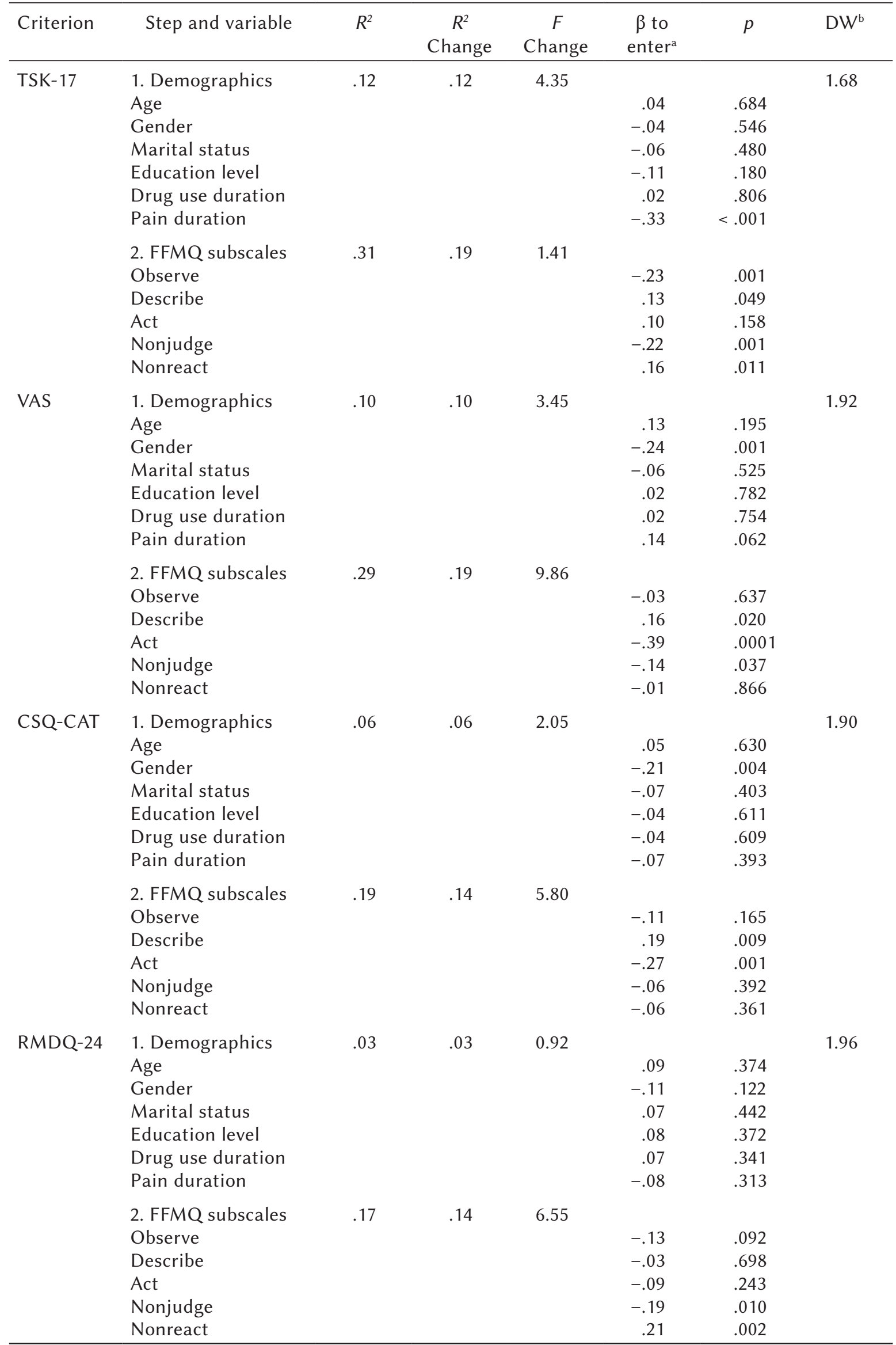

Note. ${ }^{\text {a }}$ standardized regression coefficient, ${ }^{\mathrm{b}}$ Durbin-Watson test.

Mindfulness skills and undesirable outcomes associated with chronic pain 


\section{DISCUSSION}

This study attempted to provide more information as to the effect of mindfulness skills on controlling undesirable outcomes of chronic pain, particularly in patients with musculoskeletal problems. Findings after eliminating the demographic factors and conditions related to disease pointed to the relationships between mindfulness skills and undesirable outcomes of chronic pain such as pain severity, kinesiophobia, pain catastrophizing and physical disability. Consistent with this study, other researchers, studying chronic pain patients, considered mindfulness skills as associated with the reduction of undesirable outcomes of chronic pain (Schütze et al., 2010) and increase in satisfaction with life (Henriksson et al., 2016).

Given the present results, it was found that patients with higher scores in Observing experienced less fear of movement, meaning through Observing, patients become more cognizant of other safe stimuli (such as senses, cognitions, emotions, sounds, pictures and smells), resulting in more knowledge about oneself and one's surrounding, and less fear of movement. Seemingly, greater pain severity means more interest in speaking and sharing one's experiences. It is considered that in the process of putting internal painful experiences into words, fear of more movement and catastrophizing become all the more severe. Patients with higher scores in Describing exaggerate their pain experiences so as to render their pain more noticeable, leading to more catastrophizing and fear of movement. The results of this study revealed that patients who consciously act "in the present" moment and avoid developing habits in their actions are more conscious and can take better care of themselves in a more appropriate manner - hence the reduction in their pain severity; individuals who are fully conscious in every moment, and are aware of their pain level, experience less catastrophizing statements concerning their pain and disease. As far as Non-judging is concerned, the results showed that patients who, while aware of their emotions and thoughts, do not judge them, experience lower pain severity, physical disability, and fear of movement. Finally, regarding Non-reactivity, patients inattentive to their internal experiences and not wallowing in their thoughts and emotions had more disability and fear of movement, implying that attention to thoughts and emotions can better solve the concomitant problems and tensions, reducing their negative emotional weight. As a result of reactivity to internal experiences, patients can experience more functional ability and less fear of movement, and more positively believe in themselves.

The findings of Beks et al. (2017) were not directly in line with the present results; however, they found that high levels of non-reactivity meant lower pain severity. In a study on patients with chronic pain, Poulin et al. (2016) found that high levels of non- judging and acting with awareness were associated with lower pain severity and less catastrophizing pain, which is in line with the present study. This study had certain limitations: the samples were exclusively patients with chronic musculoskeletal pain. Future studies must evaluate different aspects of mindfulness in a varied population of patients with chronic pain. What is evident is that treatments based on mindfulness originated from East Asia (KabatZinn \& Hanh, 2009) and have recently been introduced to western countries (Segal et al., 2013; Bishop et al., 2006; Azad Marzabadi \& Hashemi Zadeh, 2014; Carmody \& Baer, 2007; Sanders \& Lam, 2010; Brown \& Ryan, 2003; Herndon, 2008; Gardner-Nix, 2009) and Islamic areas of West Asia (Azad Marzabadi \& Hashemi Zadeh, 2014; Ahmadvand \& Heydarinasab, 2013; Dehghani et al., 2014) with religious contexts different from eastern Asia. Therefore, people in East Asia may be more familiar with Buddhism and concepts related to mindfulness compared with Islamic and western countries. In light of such cultural and religious differences, the reliability of results associated with different subscales of the FFMQ may decline and undergo disparity. For instance, high levels of Describing and Non-reactivity were associated with greater pain severity, fear of movement and catastrophizing and physical disability, which is in contradiction with the theoretical bases put forth by Baer et al. (2006). It is also suggested that mindfulness meditation programs be performed on patients with chronic MSP in accordance with a repeated measure before and after design.

Siegel (2010) believes that mindfulness is a way of better relating to life, which can relieve physical pain through coordination with moment-by-moment experience, and presenting direct insight as to the role of mind in generating undue concerns. In line with this idea, the present study illustrates general directions for future research. The current results can be applied in interventions based on mindfulness for patients with chronic pain. Through such studies, scholars can find that the improvement in chronic pain outcomes is, to a certain extent, related to FFMQ dimensions.

It seems that the present study is among the first formal investigations to examine the relationship between mindfulness and common outcomes of musculoskeletal pain and expand former literature through focusing on specific aspects of mindfulness in patients with chronic pain. In conclusion, different dimensions of FFMQ, namely Observing, Describing, Acting with awareness, Non-judging and Nonreactivity, are related to the common outcomes of chronic pain (such as kinesiophobia, pain catastrophizing and physical disability, and pain severity); furthermore, mindfulness interventions can potentially result in clinical improvements in patients suffering from chronic musculoskeletal pain. 


\section{ACKNOWLEDGMENTS}

The authors would like to acknowledge the research participants who so generously allocated their time.

\section{RefERENCES}

Afshar-Nezhad, T., Rezaei, S., \& Yousef-zadeh, S. (2010). The Relationship between Fear of Movement and Pain Intensity with Physical Disability in Chronic Low-Back Pain Patients. Journal of Rehabilitation, 11, 21-28. Retrieved from http://rehabilitationj.uswr.ac.ir/article-1-478-fa.html

Ahmadvand, Z., \& Heydarinasab, L. (2013). An investigation of the validity and reliability of psychometric characteristics of five facet mindfulness questionnaire in Iranian non-clinical samples. Journal of Behavioral Sciences, 7, 229-237. Retrieved from http://www.magiran.com/view.asp?Type=pdf\& ID $=1198875 \& \mid=$ en

Asgharimoghaddam, M. A. (2004). Evaluation prevalence of continuing and recurrent chronic pain and its effect on social function and life of workers in the one of Tehran's big industry. Daneshvar Raftar, 4, 1-14. Retrieved from http://cpap.shahed. ac.ir/article-1-85-en.html

Asgharimoghaddam, M., Golak, N. (2005). The role of coping strategies with pain in adjustment with chronic pain. Daneshvar Raftar, 1, 1-23. Retrieved from http://cpap.shahed.ac.ir/article-1-216-en.html

Azad Marzabadi, E. \& Hashemi Zadeh, S. M. (2014). The effectiveness of mindfulness training in improving the quality of life of the war victims with post-traumatic stress disorder (PTSD). Iranian Journal of Psychiatry, 9, 228-236.

Baer, R. A., Smith, G. T., Hopkins, J., Krietemeyer, J., \& Toney, L. (2006). Using self-report assessment methods to explore facets of mindfulness. Assessment, 13, 27-45. https://doi.org/1.1177/1073191105283504

Beks, R. B., Mellema, J. J., Menendez, M. E., Chen, N. C., Ring, D., \& Vranceanu, A. M. (2017). Does mindfulness correlate with physical function and pain intensity in patients with upper extremity illness? Hand, 13, 237-243. https://doi. org/1.1177/1558944717697429

Bishop, S. R., Lau, M., Shapiro, S., Carlson, L., Anderson, N. D., Carmody, J., Segal, Z. V., Abbey, S., Speca, M., Velting, D., \& Devins, G. (2006). Mindfulness: A proposed operational definition. Clinical Psychology: Science and Practice, 11, 230-241. https://doi.org/1.1093/clipsy.bph077

Braams, B. R., Blechert, J., Boden, M. T., \& Gross, J. J. (2012). The effects of acceptance and suppression on anticipation and receipt of painful stimulation. JournalofBehaviorTherapyandExperimentalPsychiatry, 43, 1014-1018. https://doi.org/1.1016/j.jbtep. 2012.04.001
Brown, K. W., \& Ryan, R. M. (2003). The benefits of being present: Mindfulness and its role in psychological well-being. Journal of Personality and Social Psychology, 84, 822-848. https://doi.org/1.1037/00223514.84.4.822

Carmody, J., \& Baer, R. A. (2007). Relationships between mindfulness practice and levels of mindfulness, medical and psychological symptoms and well-being in a mindfulness-based stress reduction program. Journal of Behavioral Medicine, 31, 23-33. https://doi.org/1.1007/s10865-007-9130-7

Coakes, S., Steed, L., \& Ong, C. (2010). SPSS without anguish. Milton, QLD: Wiley.

Dehghani, M., Esmaeilian, N., Akbari, F., Hassanband, M., \& Nikmanesh, E. (2014). Evaluating the psychometric and factorial structure of the five dimensional mindfulness questionnaire. Thoughts and Behavior in Clinical Psychology, 9, 77-86. Retrieved from http://jtbcp.riau.ac.ir/article_102_en.html

Falkenström, F. (2010). Studying mindfulness in experienced meditators: A quasi-experimental approach. Personality and Individual Differences, 48, 305-331. https://doi.org/1.1016/j.paid.2009.1.022

Faul, F., Erdfelder, E., Buchner, A., \& Lang, A. G. (2009). Statistical power analyses using $G^{*}$ Power 3.1: Tests for correlation and regression analyses. Behavior Research Methods, 41, 1149-1160. https:// doi.org/1.3758/brm.41.4.1149

Gardner-Nix, J. (2009). Mindfulness-Based Stress Reduction for Chronic Pain Management. In F. Didonna (Ed.), Clinical Handbook of Mindfulness (pp. 369-381). New York, NY: Springer.

Gefen, D., Straub, D. W., \& Boudreau, M. C. (2000). Structural equation modeling and regression: Guidelines for research and practice. Communications of the Association for Information Systems, 3, 1-78. https://doi.org/1.17705/1CAIS.00407

Gutke, A., Lundberg, M., Östgaard, H. C., \& Öberg, B. (2010). Impact of postpartum lumbopelvic pain on disability, pain intensity, health-related quality of life, activity level, kinesiophobia, and depressive symptoms. European Spine Journal, 20, 440-448. https://doi.org/1.1007/s00586-010-1487-6

Harvey, A. M. (1995). Classification of chronic pain - descriptions of chronic pain syndromes and definitions of pain terms. The Clinical Journal of Pain, 11, 163. https://doi.org/1.1097/00002508-199506000-00024

Henriksson, J., Wasara, E., \& Rönnlund, M. (2016). Effects of Eight-Week-Web-Based Mindfulness Training on Pain Intensity, Pain Acceptance, and Life Satisfaction in Individuals with Chronic Pain. Psychological Reports, 119, 586-607. https://doi. org/1.1177/0033294116675086

Herndon, F. (2008). Testing mindfulness with perceptual and cognitive factors: External vs. internal encoding, and the cognitive failures questionnaire. Personality and Individual Differences, 44, 32-41. https://doi.org/1.1016/j.paid.2007.07.002
Mindfulness skills and undesirable outcomes associated with chronic pain 
Jafari, H., Ebrahimi, I., Salavati, M., Kamali, M., \& Fata, L. (2010). Psychometric properties of Iranian version of Tampa Scale for Kinesiophobia in low back pain patients. Archives of Rehabilitation, 11. Retrieved from http://rehabilitationj.uswr.ac.ir/ article-1-435-fa.html

Jay, K., Brandt, M., Jakobsen, M. D., Sundstrup, E., Berthelsen, K. G., Schraefel, M. C., Sjøgaard, G., \& Andersen, L. L. (2016). Ten weeks of physical-cognitive-mindfulness training reduces fear-avoidance
Sajjad Rezaei, Sedigheh Hassanzadeh beliefs about work-related activity. Medicine, 95, e3945. https://doi.org/1.1097/md.0000000000003945

Kabat-Zinn, J. (1990). Full catastrophe living: Using the wisdom of your body and mind to face stress, pain, and illness. New York: Delacorte Press.

Kabat-Zinn, J., \& Hanh, T. N. (2009). Full catastrophe living: Using the wisdom of your body and mind to face stress, pain, and illness. New York: Delta.

Kabat-Zinn, J., Lipworth, L., Burney, R., \& Sellers, W. (1986). Four-year follow-up of a meditation-based program for the self-regulation of chronic pain: Treatment outcomes and compliance. Clinical Journal of Pain, 2, 159-173.

Keefe, F. J., \& Williams, D. A. (1990). A comparison of coping strategies in chronic pain patients in different age groups. Journal of Gerontology, 45, 161-165. https://doi.org/10.1093/geronj/45.4.P161

Lumley, M. A., Cohen, J. L., Borszcz, G. S., Cano, A., Radcliffe, A. M., Porter, L. S., Schubiner, H., \& Keefe, F. J. (2011). Pain and emotion: a biopsychosocial review of recent research. Journal of Clinical Psychology, 67, 942-968. https://doi.org/1.1002/jclp.20816

Mantzios, M., \& Egan, H. (2018). An exploratory examination of mindfulness, self-compassion, and mindful eating in relation to motivations to eat palatable foods and BMI. Health Psychology Report, 6, 207-215. https://doi.org/10.5114/hpr.2018.73052

Mousavi, S. J., Parnianpour, M., Mehdian, H., Montazeri, A., \& Mobini, B. (2006). The Oswestry Disability Index, the Roland-Morris Disability Questionnaire, and the Quebec Back Pain Disability Scale: Translation and Validation Studies of the Iranian Versions. Spine, 31, E454-E459. https://doi. org/1.1097/01.brs.0000222141.61424.f7

Ogon, M., Krismer, M., Söllner, W., Kantner-Rumplmair, W., \& Lampe, A. (1996). Chronic low back pain measurement with visual analogue scales in different settings. Pain, 64, 425-428. https://doi. org/1.1016/0304-3959(95)00208-1

Otis, J. D. (2007). Managing Chronic Pain: Therapist Guide. Oxford, NY: Oxford University Press.

Poulin, P. A., Romanow, H. C., Rahbari, N., Small, R., Smyth, C. E., Hatchard, T., Solomon, B. K., Song, X., Harris, C. A., Kowal, J., Nathan, H. J., \& Wilson, K. G. (2016). The relationship between mindfulness, pain intensity, pain catastrophizing, depression, and quality of life among cancer survivors living with chronic neuropathic pain. Supportive Care in Can- cer, 24, 4167-4175. https://doi.org/1.1007/s00520016-3243-x

Rezaei, S., Afsharnejad, T., Kafi, M., Soltani, R., \& Fallahkohan, S. (2009). Relationship between depression and coping strategies in chronic back pain patients. Daneshvar Medicine, 16, 63-74. Retrieved from http:// daneshvarmed.shahed.ac.ir/article-1-61-fa.html

Roland, M., \& Fairbank, J. (2000). The Roland-Morris Disability Questionnaire and the Oswestry Disability Questionnaire. Spine, 25, 3115-3124. https://doi.org/1.1097/00007632-200012150-00006

Rosenstiel, A. K., \& Keefe, F. J. (1983). The use of coping strategies in chronic low back pain patients: Relationship to patient characteristics and current adjustment. Pain, 17, 33-44. https://doi.org/ 1.1016/0304-3959(83)90125-2

Sanders, W. A., \& Lam, D. H. (2010). Ruminative and mindful self-focused processing modes and their impact on problem solving in dysphoric individuals. Behaviour Research and Therapy, 48, 747-753. https://doi.org/1.1016/j.brat.201.04.007

Schütze, R., Rees, C., Preece, M., \& Schütze, M. (2010). Low mindfulness predicts pain catastrophizing in a fear-avoidance model of chronic pain. Pain, 148, 120-127. https://doi.org/1.1016/j.pain.2009.1.030

Segal, Z. V., Williams, J. M. G., \& Teasdale, J. D. (2013). Mindfulness-based cognitive therapy for depression. New York: Guilford Press.

Sengupta, S., \& Kumar, D. (2005). Pain and emotion: relationship revisited. German Journal of Psychiatry, 8, 85-93.

Siegel, R. D. (2010). The mindfulness solution: Everyday practices for everyday problems. New York: Guilford Press.

Smolen, J. S. (2004). Combating the burden of musculoskeletal conditions. Annals of the Rheumatic Diseases, 63, 329-329. https://doi.org/1.1136/ard.2004.022137

Taylor, W. J., Dean, S. G., \& Siegert, R. J. (2006). Differential association of general and health self-efficacy with disability, health-related quality of life and psychological distress from musculoskeletal pain in a cross-sectional general adult population survey. Pain, 125, 225-232. https://doi.org/1.1016/j. pain.2006.05.023

Thorn, B. E. (2017). Cognitive therapy for chronic pain: A step-by-step guide. New York: Guilford Press.

Turk, D. C., \& Melzack, R. (2001). Handbook of pain assessment (2nd ed.). New York: Guilford Press.

Vlaeyen, J. W. S., Kole-Snijders, A. M. J., Rotteveel, A. M., Ruesink, R., \& Heuts, P. H. (1995). The role of fear of movement/(re)injury in pain disability. Journal of Occupational Rehabilitation, 5, 235-252. https://doi.org/10.1007/BF02109988

Walker, B. F. (2000). The prevalence of low back pain: A systematic review of the literature from 1966 to 1998. Journal of Spinal Disorders, 13, 205-217. https://doi.org/1.1097/00002517-200006000-00003 